\title{
¿HACER TABLA RASA DE LA HISTORIA?: LA ANALOGÍA ENTRE HERENCIA FISIOLÓGICA Y MEMORIA EN EL ANARQUISMO ESPAÑOL (1870-1914)
}

\author{
Álvaro Girón \\ Depto. H. ${ }^{a}$ de la Ciencia, Instituto de Historia, CSIC
}

\section{RESUMEN}

La difusión del darwinismo estimuló un gran interés sobre los fenómenos asociados con la herencia fisiológica en el período 1870-1930. Los anarquistas españoles, aunque no se interesaron específicamente por las causas de la herencia y la variación, sí manifestaron una preocupación evidente sobre sus potenciales efectos. De hecho, la analogía entre herencia y memoria, normalmente asociada con teorías neolamarckianas, fue extremadamente útil a la hora de racionalizar aquellos aspectos de la realidad histórica y social que eran más difíciles de aceptar desde un punto de vista libertario.

\section{SUMMARY}

The expansion of Darwinism stimulated a great deal of interest about the phenomena associated with heredity during the 1870-1930 years. Spanish anarchists, even though they were not specifically interested in the causes of variation and heredity, manifested an explicit concern about its potential effects. In fact, the analogy between memory and heredity, normally linked with Neolamarckian theories, proved to be extremely useful to rationalise those aspects of social and historical reality more difficult to accept from a libertarian point of view.

La introducción de ese laxo complejo que llamamos darwinismo estimuló un enorme interés sobre la herencia o más bien sobre el fenómeno global de la generación. Obviamente, antes de Darwin ya existía una larguísima historia de especulación sobre la naturaleza y causas de la herencia fisiológica. Pero con la expansión del darwinismo llega también una novedad esencial. La herencia ya no solo era importante para explicar la semejanza entre progenitores y descendencia, sino que se convirtió en elemento clave de cualquier teoria de la evolución o del origen de las especies. Ahora bien, era precisamente la falta de una teoría aceptable sobre las causas de la herencia y la variación, la que demostró ser una de las debilidades más notables 


\section{ÁLVARO GIRÓN}

del darwinismo primitivo. De hecho, hasta que se consolida la llamada revolución mendeliana a principios del siglo XX, no se puede hablar de un consenso científico emergente en torno a las causas de la variación y la herencia fisiológicas ${ }^{1}$. Si la confusión sobre la cuestión era grande dentro de la comunidad científica, no lo podía ser menos dentro del núcleo dirigente de los libertarios españoles. Uno de los anarquistas más influyentes en su época, el catalán Joan Montseny, pensaba que la herencia era «la tendencia que tiene el organismo humano a desarrollarse a semejanza de los que lo engendraron $»^{2}$. Sin embargo, aquí se establecían distinciones no siempre claras. El propio Joan Montseny afirmaba «que la ley de herencia existe para el cuerpo», mientras que «las cualidades que necesariamente han de residir en el modo de ser del cerebro, nacen y mueren en el mismo individuo» ${ }^{3}$.

De hecho, los anarquistas españoles ciertamente no estaban interesados en el fenómeno general de la herencia. Cuando se hablaba de ley de herencia se estaba pensando en humanos, no en animales y plantas. Y aún ahí el nivel de coherencia no era especialmente grande. En realidad lo que se heredaba y lo que no se heredaba dependía decisivamente de lo que se hablaba en cada momento. Cuando se trataba de oponerse desde una posición ambientalista a las teorías de Cesare Lombroso y su escuela, se negaba tajantemente la posibilidad de heredabilidad de la conducta criminal ${ }^{4}$. Y, sin embargo, cuando había que explicar lo inexplicable, la presencia dentro de un Pueblo sacralizado - $\mathrm{O}$ incluso dentro del reducido núcleo de obreros conscientes-, de conductas y actitudes opuestas al ideal libertario, se hablaba sin tapujos del influjo de la regresiva herencia e incluso de un atavismo que a veces nos retrotrae a un pasado prehumano. Así, el patriarca del anarquismo español, Anselmo Lorenzo, quien definía el atavismo como «la reproducción individual o en parte de estados fisiológicos y morales, propios de épocas pasadas, diferentes del medio ambiente», afirmaba que éste no sólo explica la existencia de la súbita reaparición del «hombre con cola

1 La sensación de fracaso científico generalizado, en lo que respecta a la teoría de la herencia, es visible en el filósofo evolucionista Herbert Spencer: «En la reedición de la Biología (...) hace notar que (...) fracasan sin remisión todas las teorías de la herencia establecidas, la teoría «pangenésica» darwiniana, la de la «continuidad del plasma germinal» de Weismann, y lo mismo su propia teoría de las «unidades fisiológicas», y llega a la siguiente conclusión: «Tenemos que reconocer sencillamente que el fenómeno de la herencia excede a toda comprensión. No basta decir: no lo conocemos. Debemos decir: no podemos ni siquiera comprenderlo»». Citado en GAUPP, O. (1930), Spencer, Madrid, pp. 182-183.

2 Montseny, J. (1896), Sociología anarquista, La Coruña, p. 80.

3 MONTSENY, J. (1896), p.71.

4 Sobre la introducción de las ideas criminológicas de Césare Lombroso en España: MARISTANY, L. (1973), El gabinete del doctor Lombroso. (Delincuencia y fin de siglo en España), Barcelona. Sobre la oposición de los anarquistas españoles a las tesis lombrosianas y sus aplicaciones: GALERA, A. (1988), «Acracia y Antropología Criminal: ciencia y revolución social decimonónica», Asclepio, XL, fascículo 2, 247-266; GAlerA, A. (1991), Ciencia y delincuencia, Sevilla, CSIC, 111-140; GALERA, A. (1995), «La antropología criminal frente al anarquismo español» en HoFMANN, B, JOAN I TOUS, P. y TIETZ, M. (eds.), El anarquismo español y sus tradiciones culturales, Frankfurt y Madrid, Vervuert-Iberoamericana, 109-120. 
(...) y pies como garras», sino también del «impúdico, el incestuoso y hasta el antropófago, lo mismo entre las gentes incultas que entre los que han recibido educación más distinguida» ${ }^{5}$. Así pues, mas que una visión coherente sobre los fenómenos de la herencia, se usaban distintas versiones de su rol biológico e histórico en función del contexto inmediato. En este artículo exploraremos la explotación ideológica de la analogía entre herencia y memoria que, como veremos, permite racionalizar algunos aspectos especialmente molestos del presente y pasado históricos.

Lógicamente, hay que referirse al marco teórico implícito dentro del cual se desarrollaba dicho uso. Lo primero que hay que decir, es que no hay indicios de que el redescubrimiento de las leyes de Mendel en torno a $1900^{6}$ causaran ningún efecto en los medios libertarios. Ello no debe extrañar, teniendo en cuenta que el Mendelismo no fue recibido con especial entusiasmo fuera de la comunidad científica anglosajo$\mathrm{na}^{7}$. Algo parecido se puede decir de la teoría del plasma germinal que August Weismann desarrolló a lo largo de los años 1880, y que venía a postular que el cuerpo era incapaz de influir en la información genética que pasaba de una generación a otra $^{8}$. Se estaba muy lejos de establecer una distinción neta entre genotipo y fenotipo:

5 LORENZO, A. (1904), «Atávico, misoneista, precursor», Almanaque de la Revista Blanca para 1903, 48-49; pp. 48-49. El atavismo, permite, incluso, explicar la conducta aparentemente aberrante de los niños. Tal es el caso del anarquista gaditano Fermín Salvoechea, quien en su folleto La contribución de la sangre (1900), afirmaba que «la manera instructiva con que el niño persigue a la mariposa y en su bobo deseo de apoderarse de todos los organismos inferiores que le rodean, se nota claramente la fuerza de la herencia y el lazo que nos une con nuestros antepasados los demás animales...» Citado en MORENO APARICIO, I. (1982), Aproximación histórica a Fermín Salvoechea, Cádiz, pp. 275-276.

6 Actualmente se cuestiona hasta que punto Gregor Mendel puede ser considerado un mendeliano bajo los criterios que empezaron a popularizarse a partir de 1900. Sobre la cuestión: OLBY, R.C. (1979), «Mendel no Mendelian?, History of Science, 17, 53-72; SANDLER, I. y SANDLER, L. (1985), «A Conceptual Ambiguity that Contribuited to the Neglect of Mendel's Paper, History and Philosophy of Life Science, 16, 311-342.

7 La idea de que la herencia mendeliana solo se limitaba a caracteres menores y no a aquellos que son fundamentales para definir al organismo y la especie estaba muy extendida: SAPP. J.(1987), Beyond the Gene. Cyoplasmic Inheritance and the Struggle for Authority in Genetics, Oxford, p. 16. Para una visión general sobre la cuestión: SAPP, Jan (1983), «The Struggle for Authority in the Field of Heredity, 1900-1932: New Perspectives on the Rise of Genetics», Journal of the History of Biology, 16, 311-342. Para el caso alemán. HARwOOD, J. (1993), Styles of Scientific Thought. The German Genetics Community, Chicago, p. 105. En el caso francés: BURIAN, R.M., GAYON, J. y ZALLEN, P. (1988), «The Singular Fate of Genetics in the History of French Biology», Journal of the History of Biology, 23, 357-402.

8 Weismann, además, eliminó del darwinismo todas las influencias lamarckianas originales, afirmando que la selección natural era el único mecanismo evolutivo. La definición extremadamente laxa de lo que se entendía por darwinismo dio paso a otro mucho más rígidamente seleccionista. El campo de la biología evolucionista se dividió entre neodarwinistas y neolamarckianos (vid. al respecto: BOWLER, P.J. (1985), El eclipse del darwinismo. Teorías evolucionistas antidarwinistas en las décadas en torno a 1900, Barcelona, Labor, pp. 50 y 149; RADL, E.M. (1988), Historia de las teorías biológicas. 2. Desde Lamarck y Cuvier, Madrid, Alianza, p. 302.). El neodarwinismo encontró pronto poderosos enemigos en el antiguo campo darwinista. El caso más llamativo es el del filósofo inglés Herbert Spencer, para quien 
no se podía concebir la idea de que la constitución genética del individuo (su genotipo) no se refleja necesariamente en su apariencia física (su fenotipo) ${ }^{9}$. Los anarquistas, como la inmensa mayoría de sus contemporáneos, trabajaban dentro de los límites de una tradición premendeliana que veía al organismo como un sistema integrado y autorregulado. Una tradición en la que era inconcebible el pensar en que el material genético estuviese completamente aislado del cuerpo. Una forma de ver la cuestión que inducía a pensar que toda teoría que tratase de explicar la herencia y la variación debía comprender el proceso de desarrollo individual.

Desde este punto de vista, la variación debía de producirse en conexión con alguna distorsión en el proceso de desarrollo individual o en la embriogenia, y no, como se postuló posteriormente, como un evento que habría de suceder en el propio material genético. Ciertamente, se podría pensar que las variaciones ocasionadas por dichas distorsiones podrían ser azarosas (opción preferida por el propio Darwin ${ }^{10}$ ), pero

negar la herencia de los caracteres adquiridos era como «poner en duda la posibilidad misma de la evolución biológica.» Citado en GAUPP, O. (1930), Spencer, Madrid, p. 30 (Vid. también: CHURCHILL, F.B. (1978), «The Weismann-Spencer Controversy over the Inheritance of Acquired Characters», en FORBES, E.G. (ed.), Human Implications of Scientific Advance. Proceedings of the XVth International Congress of the History of Science, Edimburgo, 451-464. En todo caso, hay que decir que la teoría de Weismann no fue aceptada en su momento de manera masiva, entre otras cosas porque los detalles de su teoría no pudieron ser confirmados experimentalmente (MAIENSCHEIN, J. (1991), «Epistemic Styles in German and American Embriology», Science in Context, 4, 407-427; pp. 416-417. Por otra parte, aunque algunos reputados biólogos lo consideran como el moderno fundador de las teorías sobre la herencia (MAYR, E. (1985), «Weismann and Evolution», Journal of the History of Biology, 18, 239-295 y en una linea parecida: HeGEL, R-D., (1992), «August Weismann one of the First Synthetic Theorists of Evolutionary Biology», en WoOdWard, W.R. y CoHEN, R. (eds.), World Views and Scientific Discipline Formation, Dordrecht, 259-267), historiadores de la ciencia como Peter J. Bowler consideran que el biólogo alemán no dió el paso decisivo que si dieron los mendelianos: operar una clara ruptura entre el proceso de desarrollo y la transmisión de caractéres. Vid. BOWLER, P. (1992), The Non-Darwinian Revolution, Londres y Baltimore, pp. 116-117.

9 Como es bien sabido, existen dos hechos puestos en evidencia por los experimentos de Mendel con los guisantes que hacen posible pensar en esos términos: a) los caracteres de los progenitores no se mezclan -como era la creencia común- sino que se transmiten sin cambios de una generación a otra; b) algunos caracteres recesivos pueden ser enmascarados por sus equivalentes dominantes o alelos, pero pueden reaparecer sin cambios en las generaciones posteriores. La distinción entre genotipo y fenotipo fue acuñada en 1909 por Wilhelm Johannsen: Vid. JOHANNSEN, W. (1911), «The Genotype Conception of Heredity», American Naturalist, 45, 129-159; WANSCHER, J.H. (1975), «The History of Wilhelm Johansenn's Genetical Terms and Concepts from the Period 1903 to 1926», Centaurus, 19, 125-147; CHURCHILL, W. (1974), «William Johansenn and the Genotype Concept», Journal of the History of Biology, 7, 5-30; GudDING, G. (1996), «The Phenotype/Genotype Distinction and the Dissapearence of the Body», Journal of the History of Ideas, 57, 525-545.

10 La historiografía clásica sobre Darwin ha destacado normalmente aquellos aspectos de la teoría que son más coherentes con nuestra visión moderna del darwinismo. Desde este punto de vista, se destacan los estudios biogeográficos de Darwin y se le suele presentar como naturalista. Sin embargo, algunos autores han señalado que sus estudios sobre la fisiología de la reproducción, llevados a cabo dentro de 
también se podía suponer que dichas variaciones representan el desarrollo en el organismo de una respuesta positiva a algún desafío ambiental. Esta última versión era la preferida por los anarquistas españoles en todo lo referente a la herencia humana. De hecho, herencia, variación, y herencia de los caracteres adquiridos parecían una misma cosa a ojos de nuestros libertarios ${ }^{11}$.

Dicha preferencia implícita o explícita por una posición lamarckiana no debe extrañar. Encontraba, en primer lugar, un sólido apoyo dentro del consenso darwinista inicial. Un consenso extraordinariamente flexible, que concedía un papel importante a la herencia de los caracteres adquiridos. Los sistemas biológicos y filosóficos de dos figuras eminentes en la época, Ernst Haeckel y Herbert Spencer, descansaban, en gran medida, sobre una posición neolamarckiana en todo lo referente a la herencia ${ }^{12}$. El propio Darwin concedió un papel creciente a la herencia de los caracteres adquiridos. La Medicina del momento venía a ofrecer un buen número de testimonios que se utilizaban en favor de la misma ${ }^{13}$. De hecho, si se pasaba por alto —como en este

una tradición muy distinta al enfoque de la Genética moderna, fueron de gran importancia: la evolución no sólo era función de la geografía y la adaptación, sino del crecimiento y la reproducción. Vid. al respecto: HodGE, M.J.S. (1985), «Darwin as a Lifelong Generation Theorist», en KoHN, D. (ed), The Darwinian Heritage, Princeton, 207-244. Vid. también: HODGE, M.J.S. (1989), «Generation and the Origin of Species: A Historiographical Suggestion», British Journal of the History of Science, 22, 267-281.

11 En la influyente Revista Social, por ejemplo, se leía en 1882 que la «influencia del medio produce al principio ciertos cambios en la organización» que «después se transmiten a los sucesores acentuándose más». Redacción (1882), «Arte y Ciencias. Carlos Darwin», La Revista Social, 50,3. Este tipo de identificación se daba entre importantes divulgadores de la ciencia como Ludwig Büchner. Su caso es especialmente relevante por la influencia directa que tuvo en anarquistas como Gaspar Sentiñón. Según Büchner, todo lo referente a la tendencia a variar de los organismos no tendría valor alguno, «si no estuviera apoyado por la transmisión o facultad de heredar las modificaciones adquiridas. (Atavismus, Hereditas)». BÜCHNER, L. (1871), «Sección doctrinal. La teoría darwiniana», La Humanidad, 31, 247-248; p. 248.

12 Bowler, P.J. (1985), El eclipse del darwinismo. Teorías evolucionistas antidarwinistas en las décadas en torno a 1900, Barcelona, pp. 81-82; GAUPP (1930), p. 181. Hay que tener en cuenta que la creencia en la herencia de los caracteres adquiridos, es decir la idea de que «los caracteres que se adquieren accidentalmente, accidentalmente se pierden, mientras que aquellos que perduran con el tiempo se terminan fijando en la especie o variedad», estaba muy extendida en Europa mucho tiempo antes de que Lamarck y Darwin lo incorporaran «a sus esquemas especulativos.»CASTRODEZA, C. (1988), Teoría histórica de la selección natural, Madrid, p. 175.

13 No hay que olvidar el papel clave de la Medicina del XIX, en especial la francesa, a la hora de consolidar y difundir muchas de las ideas más aceptadas sobre la herencia. Los fenómenos generales asociados con lo hereditario, que los médicos habían reconocido y que trataban de considerar luego para su tratamiento de lo patológico, fueron luego vistas como también importantes para una comprensión de lo normal. Según López Beltrán la «primera estructura de nuestro moderno concepto de herencia biológica fue (...) proporcionada por estas distinciones médicas.» LÓPEZ BELTRÁN, C. (1994), «Forging Heredity: From Metaphor to Cause. A Reification Story», Studies in History and Philosophy of Science, 25, 211-235. Lo interesante, desde nuestro punto de vista, es que una gran parte de los médicos de la época pensaban que las enfermedades o sus consecuencias debilitadoras podían ser heredadas. De hecho, como 


\section{ÁLVARO GIRÓN}

caso-, la escisión del campo evolucionista que provocó la difusión de la teoría de Weismann a partir de los años 1880, se podía ser darwinista y aceptar a la vez la herencia de los caracteres adquiridos.

Por otra parte, a primera vista, una posición blanda en lo referente a la herencia tiene indudables ventajas políticas. No pocos veían en la criminalidad, la locura, la degeneración o la desigualdad humana, como la mera proyección a la realidad social de las diversas capacidades o discapacidades innatas de los individuos que eran, por definición, fijas y esenciales. Frente a ello, la utilización de la herencia de los caracteres adquiridos que hacían los anarquistas españoles, era solidaria de un ambientalismo extremo que subrayaba la maleabilidad de la naturaleza humana. Joan Montseny, más conocido por su seudónimo Federico Urales, afirmaba, por ejemplo que «los agentes exteriores que dan vida a mi vida, tienen más influencia en mi ser que la propia primera sustancia que dio vida y forma a mi persona» ${ }^{14}$. El teórico anarquista Ricardo Mella creía que se «ha demostrado, principalmente por Darwin, que el cambio de condiciones, influye soberanamente en el organismo físico...» ${ }^{15}$

No sólo se trataba de desacreditar la idea de que la estructura social fuera un fiel reflejo del desigual reparto de dones naturales. Subyacía, además, el problema de que las teorías duras de la herencia solían verse como una forma de legitimación de un hereditarismo extremo. La creencia de que las capacidades físicas y psicológicas de los individuos estaban rígidamente predeterminadas $a b$ initio, venía no sólo a sugerir la idea de que la educación, el esfuerzo de mejora individual o la propia acción política tenían efectos inevitablemente limitados o simplemente nulos. Podía ofrecer legitimidad a especulaciones y a políticas concretas, que van desde el terreno de la eugenesia al Derecho Penal, orientadas por la idea general de que la única forma de asegurar un mínimo de calidad biológica en las poblaciones humanas, pasaba por la progresiva eliminación de aquellos linajes humanos irremediablemente ineptos. La ansiedad ante esta amenaza se refleja claramente en un destacado personaje ligado al anarquismo madrileño, Ernesto Alvarez:

«Admitida la criminalidad como "pecado original", como triste legado hereditario, no hay necesidad de reformar los usos y las costumbres, cambiar las condiciones sociales (...) ¿Para qué? ¿Cómo alterar las leyes naturales? ¿Cómo extirpar socialmente aquel delito que tiene su origen en los misterios de la concepción y su guarida en el claustro materno?»16

afirma Peter J. Bowler, «los médicos no distinguían entre lo que llamamos herencia y la transmisión de un efecto de la madre durante el proceso de crecimiento: ambos eran considerados aspectos de un concepto de herencia mucho más amplio.» BOWLER (1985), p. 80.

14 MONTSENY, J. (1896), p. 80.

15 Mella, R. (1901), La coacción moral, Madrid, pp. 31-32.

16 Alvarez, E. (1896), «Bibliografía», La Idea Libre, 104, 2; p.2. Ernesto Alvarez es más conocido como editor y director de revistas que como autor de folletos y artículos. Su nombre aparece vinculado a casi todas las publicaciones libertarias aparecidas en Madrid. Colabora entre 1881 y 1885 con Serrano 
Por el contrario, una posición neolamarckiana podía ser utilizada para asegurar que hay una continua retroalimentación entre naturaleza y medio social, entre herencia y medio. Un nuevo carácter sólo puede ser adquirido si el organismo no está rígidamente determinado por la herencia. Los efectos continuados del esfuerzo individual, la educación o la acción política podían tener efectos positivos en la materia indefinidamente proteica de los individuos. Y no sólo eso, la idea de que el nuevo carácter - positivo - pueda ser fijado por la herencia permitía pensar que los efectos beneficiosos de las mejoras introducidas en el ambiente podrían llegar a tener un valor cuasi permanente para el stock biológico de la raza. Urales, por ejemplo, pensaba que «mejorando» el ambiente, se mejoraba «la salud de los que van a ser padres y los prepara para engendrar seres más sanos y fuertes» ${ }^{17}$. Mella, inspirado por Spencer, piensa en un futuro utópico en que el sentimiento de obligación, residuo internalizado de la coacción social, desaparecería en un futuro no determinado ${ }^{18}$. Progreso social y progreso biológico iban necesariamente de la mano, siendo el último, en la mayoría de las ocasiones, una consecuencia del primero.

Pero si una posición neolamarckiana podía ser utilizada para asegurar un horizonte optimista para la sociedad futura, la sociedad post-revolucionaria, también podía servir para dar cobertura a un diagnóstico pesimista — moral, biológico y social— sobre los efectos nefastos de las formas de organización social presentes y pasadas ${ }^{19}$. En el caso que nos ocupa, el pensar que la herencia no era sino un «ambiente retrospectivo» ${ }^{20}$, permitía imputar a la acción del medio social la mayoría de los males presentes en los organismos y mentes de los individuos: si la degeneración y sus

Oteiza en la redacción de la Revista Social. En Madrid dirige luego Bandera Social (1885-1887), Bandera Roja_(1888-1889), La Anarquía y La Idea Libre (1894-1899). Finalmente, se encargará de la publicación de La Protesta, aparecida primitivamente en Valladolid (1899), y posteriormente en Algeciras entre 1901 y 1902. Vid. Aubert, P.; Brey, G: Guereña, J.L.; Maurice, J. y SAlaun, S. (1986), Anarquismo y poesía en Cádiz bajo la Restauración, Córdoba, pp. 66-67.

17 URALES, F. (1902)a., «La evolución de la filosofía en España», La Revista Blanca, 94, 673-677; p. 674.

18 Vid. al respecto: GIRÓN, A. (1994), «Anarquismo y evolucionismo: Ricardo Mella, la coacción del grupo social y la creación sociobiológica del hombre nuevo», Asclepio, 46, 131-149.

19 De hecho, la conexión entre lamarckismo y meliorismo social no es siempre tan clara, como señala Greta Jones. En un artículo aparecido en Mind en 1876, Spencer evidenciaba como el uso-herencia podría producir un determinismo tan acusado como el de otras teorías de la herencia alternativas. Ciertamente las instituciones moldean el carácter, pero los efectos de este moldeamiento podrían atrapar las disposiciones individuales y colectivas, en un conjunto de roles permanentes o incluso facultades, de las cuales sólo se podría escapar después de un largo proceso histórico. JonES, G. (1980), Social Darwinism and English Thought. The Interaction between Biological and Social Theory, Brighton, pp. 82-83.

20 URALES, F. (1902)b., «La evolución de la filosofía en España», La Revista Blanca, 89, 513-516; p. 514 . 


\section{ÁLVARO GIRÓN}

diversas manifestaciones existen, ello se debe a causas que remiten en última instancia a una defectuosa forma de organización social21.

Ahora bien, conviene establecer claramente los límites de esta lealtad con respecto a los mecanismos lamarckianos de variación y herencia. Nada hay parecido a un debate sobre las distintas versiones de la teoría de la herencia que empezaron a circular en las últimas décadas del XIX y las primeras del XX. No parece que los anarquistas españoles estuviesen interesados o, simplemente, conocieran los detalles del debate entre neolamarckianos y sus oponentes ${ }^{22}$. De hecho, en este debate se implicó el teórico anarquista más importante del momento, el ruso Pedro Kropotkin, quien, aparte de criticar ferozmente a Weismann, defendía una síntesis entre lamarckismo y darwinismo en donde la selección natural ocupaba un papel subordinado con respecto a la acción directa del medio sobre los organismos. Sin embargo, los anarquistas españoles, normalmente dados a traducir todo lo que salía de la pluma de Kropotkin, no hicieron mención a la importante serie de artículos del ruso sobre la cuestión ${ }^{23}$. Dicho de otra forma, aunque de las fuentes se pueda deducir que se acepta explícita-

21 Vid. al respecto: GIRÓN, A. (1999). «Metáforas finiseculares del declive biológico: degeneración y revolución en el anarquismo español», Asclepio, 51, 247-273.

22 De manera oscura, en alguna ocasión se hace referencia a la herencia de los caracteres adquiridos como posible alternativa a la «falsa» teoría de la lucha por la existencia. Tal es el caso de Anselmo Lorenzo que, de manera muy confusa, menciona como mecanismos evolutivos distintos del combate por la vida a la «herencia» y a la «selección natural (sic), o adaptación transmitida hereditariamente de todas las influencias que gravitan sobre el ser viviente...» LORENZO, A. (1890)a., «La revolución es la paz», en Segundo Certamen Socialista, Barcelona, 147-156; p. 155. En realidad Lorenzo no hace sino seguir de cerca, o incluso parafrasear, fragmentos e ideas de la obra del francés, Louis Dramard, Transformisme et socialisme (1882). La diferencia es que Dramard era mucho mas explicitamente neolamarckiano, afirmando entre otras cosas que «Jean Lamarck» se «muestra superior a los darwinistas». Vid. DRAMARD, L. (1882), Transformisme et socialisme, Paris, p. 88. La existencia de la obra de Dramard pudo ser conocida por Anselmo Lorenzo a través de La Revue Socialiste, de la cual Lorenzo traduce algunos textos luego publicados en Acracia. Aunque La Revue Socialiste se situaba en la órbita del socialismo reformista, Dramard se presentaba a si mismo como cercano al Partido Obrero de tendencia guesdista. DRAMARD (1882), p. 24. Más explícitamente lamarckiana se muestra la primera directora de la Escuela Moderna, la francesa Cleménce Jacquinet, quien al contrastar las figuras de Lamarck y Darwin llega a afirmar que «la obra filosófica de Darwin ha sido nefasta entre todas...» JACQUINET, C. (1904)a, «Ciencia falsa», El Productor, 59, 1; p.1.

23 Los artículos de Kropotkin fueron publicados en la importante revista mensual, The Nineteenth Century a lo largo de la década de los años 1910: KROPOTKIN, P. (1910), «The Theory of Evolution and Mutual Aid», The Nineteenth Century and After, CCCXCV, 86-107; KROPOTKIN, P. (1910), «The Response of the Animals to their Environment», The Nineteenth Century and After, CCCCV, 856-867; KROPOTKIN, P. (1912), «Inheritance of Acquired Characters. Theoretical Difficulties», The Nineteenth Century and After, CCCCXXII, 511-531; KROPOTKIN, P. (1910), «The Direct Action of Environment on Plants», The Nineteenth Century and After, CCCCI, 58-77; KROPOTKIN, P. (1914), «Inherited Variation in Plants», The Nineteenth Century and After, CCCCLII, 816-836; KROPOTKIN, P. (1915), «Inherited Variation in Animals», The Nineteenth Century and After, CCCCLXV, 1124-1144; KROPOTKIN, P. (1919), «The Direct Action of Environment and Evolution», The Nineteenth Century and After, DIII, 70-89. 
mente o implícitamente una posición lamarckiana, ello no implica que los libertarios españoles hicieran del lamarckismo una bandera científico-política. La opción por una visión lamarckiana de la herencia se establece más en un nivel casi inconsciente, como la derivación casi natural de ver el organismo como un todo autorregulado en donde el material hereditario es de alguna forma manufacturado por los organismos de los padres. Y de ahí solo falta un paso para pensar que dicho material hereditario memorizaría de alguna forma las alteraciones sufridas por el cuerpo de los progenitores.

De hecho, en algunas ocasiones se hizo explícita este estrecha analogía entre herencia y memoria. Ello se hace patente, tanto en personajes cercanos al movimiento libertario español como en intelectuales a los que se tenía en gran estima. Por ejemplo, la primera directora de la Escuela Moderna, la francesa Cleménce Jacquinet, afirmaba que «la herencia (...) no es más que un recuerdo, una memoria inconsciente ${ }^{24}$. Autores de frecuente lectura entre los anarquistas españoles, como es el caso de Max Nordau, precisaban aún mas el sentido de esta analogía cuando señalaban que la «herencia viene a ser respecto de la especie lo que la memoria es para el individuo» 25

No son afirmaciones desconectadas del clima intelectual científico y cultural de la época. Las llamadas teorías mnémicas de la herencia, ligadas con el interés creciente por los procesos inconscientes, gozaron de una enorme popularidad entre 1870 y $1930^{26}$. De entre aquellos científicos que elaboraron un punto de vista semejante sobre la herencia, destaca, una vez más, la figura de Ernst Haeckel ${ }^{27}$. Pero Haeckel no sólo estableció una explícita conexión entre herencia y memoria. La llamada ley biogenética fundamental, más conocida como teoría de la recapitulación, tuvo una enorme influencia durante las últimas décadas del XIX. Su postulado fundamental era que «la historia de la evolución individual, o la ontogenia, es una breve y rápida repetición, o una recapitulación de la historia evolutiva, paleontológica, o sea de la filogenia...» ${ }^{28}$ En los dominios de la Psicología y Antropología, la aplicación de la

24 JACQUINET, C. (1902), «La educación rectifica la herencia», Boletín de la Escuela Moderna, 4, $41-44 ;$ p. 43.

25 NORDAU, M. (1887a), «Las mentiras convencionales de nuestra civilización», Acracia, 21, 313 322; p. 317. Según Lilly Litvak, el autor alemán Max Nordau estuvo muy conectado con los círculos intelectuales españoles. La primera obra de Nordau traducida al español fue precisamente Las mentiras convencionales de nuestra civilización, realizada por Salmerón en 1887 (LITVAK, L. (1990), «Modernismo, anarquismo y fin de siglo», pp. 113 y 124.). En el caso de los anarquistas españoles es significativo señalar el entusiasmo de Anselmo Lorenzo ante la obra de Nordau citada (Vid. NORDAU, M. (1887b), «Las mentiras convencionales de nuestra civilización», Acracia, 29, 569-575; p. 575.).

26 Vid. al respecto: GAYON, J. (1992), "Animalité et végétalité dans les représentations de l'hérédité», Revue de Synthese, 3-4, 423-438.

27 Vid, al respecto: BOWLER, P.J. (1992), p. 84.

28 HAECKEL, E. (1878), «Sentido y significación del sistema genealógico, o teoría de la descendencia», La Revista Europea, 228, 1-9; p. 9. Como es bien sabido la teoría de la recapitulación no es original de Haeckel (vid. Radl (1988), pp. 207-209; MENGAL, P. (1993), «Introduction», en MENGAL P. (coord), 


\section{ÁLVARO GIRÓN}

teoría a la psicogénesis indujo a representar la mente como una sucesión de estratos en la que los inferiores corresponden con los más primitivos desde el punto de vista evolutivo $^{29}$. Dicho de otra forma, en lo más profundo del hombre civilizado subsisten el animal y el salvaje, aún cuando no se sea plenamente consciente de ello. Ciertamente, dada la imagen usualmente peyorativa del primitivo y del animal, este enfoque teórico llevaba al pesimismo. Mientras que los instintos ancestrales y feroces habitaban en estratos profundos de nuestra mente, lo más recientemente adquirido por efecto de la civilización y la educación, sólo era una capa superficial que disfrazaba o ocultaba la naturaleza antisocial del homo sapiens ${ }^{30}$.

Por otra parte, dicho pesimismo enlazaba con un tipo de literatura que conectaba explícitamente herencia y perdición. Autores de gran predicamento en el anarquismo hispano, como es el caso de Ibsen o Zola ${ }^{31}$, recogían en el vocabulario cientifista de

Histoire du concept de récapitulation. Ontogenèse et Philogenèse en biologie et sciences humaines, Paris, 1-4; pp. 2-3.). Sin embargo, hay muy pocas dudas de que en Haeckel ocupaba un papel central, y que pocos biólogos como él gozaron de una popularidad tan grande fuera de los medios científicos. Un ejemplo de cómo se vulgarizaba dicho concepto en los medios próximos a los libertarios nos lo da una vez más Cleménce Jacquinet: «...la vida de cada uno recuerda sumariamente la historia de la raza a que pertenecemos.» JACQUINET, C. (1903), «La primera humanidad», Natura, 6, 81-85; p. 83.

29 Esta aplicación de la teoría de la recapitulación fue ampliamente usada por los criminalistas de la escuela lombrosiana. Tal es el caso de A. Nicéforo: «La teoría de la estratitificación del carácter aparece confirmada por los estudios de psicología infantil (...) El salvaje es un niño grande; el niño es un salvaje en miniatura. Todos, por consiguiente, llevamos en el fondo de nuestro carácter estratificaciones animales y bárbaras, donde yacen los sentimientos propios del animal y del salvaje.» NiCÉFORO, A. (1902), Las transformaciones del delito, Madrid, pp. 136-137. Para tener una imagen más elaborada de la aplicación de la teoría de la recapitulación por parte de Lombroso: PESET, J. y PESET, M. (1975), Lombroso y la escuela positivista italiana, Madrid, CSIC, pp. 254-255.

30 Según G. Sergi, famoso positivista italiano y profesor de Antropología y Psicología en la Universidad de Roma, la «evolución no ha destruido los sentimientos primitivos antisociales y feroces, sino que los ha reprimido solamente, ocultado o disfrazado...» SERGI, G. (1906), Las emociones, Madrid, p. 486. Por otro lado, la adopción de un punto de vista recapitulacionista en Psicología y Psiquiatría no tiene nada de excepcional (vid. MENGAL, P. (1993)b., «Psychologie et loi de récapitulation», en MENGAL, P. (coord.), Historie du concept de recapitulation. Ontogenèse et Philogenèse en biologie et sciences humaines, París, 93-109. George J. Romanes, discípulo de Darwin, lo adoptó claramente (BowLER (1992), p. 192.). El propio Freud también sufrió una profunda influencia haeckeliana: vid. GoULD, S.J. (1977), Ontogeny and Phylogeny, Cambridge, Harvard Univ. Press, capítulo quinto; RITVO, L. (1992), L'ascendant de Darwin sur Freud, París, capítulo quinto.

31 RADL, E.M. (1988), p. 300. Según Francisco de Luis la obra de Ibsen Un enemigo del pueblo fue considerada por los libertarios como uno de sus «clásicos». Las obras de Zola también se adaptaron al teatro anarquista. DE LUIS, F. (1994), Cincuenta años de cultura obrera en España 1890-1940, Madrid, p. 28. Vid. también LiTVAK, L. (1981), Musa libertaria. Arte, literatura y vida cultural del anarquismo español (1890-1913), Barcelona, pp. 213-252. Ya en el período 1886-1888 (en la revista Acracia) se hacen varias referencias a la obra de Zola (SERRANO, C. (1995), «Acracia, los anarquistas y la cultura», en Hofmann. B., Joan i Tous, P. y Tietz, M. (eds), El anarquismo español y sus tradiciones culturales, Frankfurt y Madrid, Vervuert-Iberoamericana, 347-360; p. 351). 
la época un tema de resonancias ancestrales que ya estaba presente en la tragedia griega o en la Biblia Se trataba de la idea de que el individuo «está sujeto a fuerzas más altas, a fuerzas que vienen de atrás, de tiempos en que el individuo no existía» ${ }^{32}$. Esta corriente de pensamiento era bien conocida por los anarquistas españoles. De hecho, en la revista Acracia aparece un texto de Max Nordau que resume a la perfección un determinado clima intelectual:

«En cada ser viven las ideas de los antepasados bajo la forma de recuerdos frecuentemente inconscientes u obscurecidos, pero siempre presentes, bastando un impulso exterior para manifestarse y dominarle; y tan impotentes somos para sustraernos a su yugo como de determinar los rasgos de nuestra fisonomía y nuestro cuerpo» ${ }^{33}$.

Ciertamente, los anarquistas españoles no estuvieron preocupados tanto por el proceso concreto por el que reaparece nuestro pasado más primitivo, como por sus consecuencias. Constituyéndose la animalidad en el polo negativo del devenir histórico del homo sapiens, cabe atribuir a su reaparición súbita todo aquello que no puede ser admitido por una dogmática racionalista. La guerra, por ejemplo, es concebida como un retorno a la brutalidad primitiva ${ }^{34}$. Pero más allá de esto, es en los principios que rigen la propia forma de organización social, representada por la triada el Estado-Propiedad-Religión, donde es más perceptible la fuerza subterránea de la bestialidad atávica. Así lo afirma Josep Prat en 1907:

«...la llamada "cuestión social" es un problema humano. Es toda la humanidad, son todas las clases sociales de esta pobre humanidad doliente las que tienen que liberarse de la herencia de bestialidad que nos dejaron los animales inferiores, y cuyos bajos sentimientos palpitan todavía en nuestras vetustas instituciones religiosas, políticas y económicas...» ${ }^{35}$

Ahora bien, la emancipación no es tarea fácil. La idea, es decir, la penetración del ideal anarquista en el Pueblo, se ve obstaculizada por el contrapeso de dicha herencia bestial. Pero no sólo en el Pueblo. La contradicción entre la teoría y la praxis en el núcleo de los obreros conscientes, la evidencia de que la resocialización radical impulsada por la subcultura anarquista no ha conseguido quebrar la contradicción entre

32 RADL, E.M. (1988), p. 296.

33 NORDAU, M. (1887a), pp. 317 y 318.

34 Vid. al respecto NUÑEZ FlORENCIO, R. (1994), Utopistas y antiautoritarios en 1900, Madrid, p. 51. Las referencias a la guerra como un regreso a la animalidad primitiva o a nuestro pasado salvaje, son relativamente frecuentes en los libros de propaganda antimilitarista como Antimilitarismo reivindicado por los firmantes (1904), Patriotismo y colonización (1904) y Cuaderno Manuscrito. Recapitulación de pensamientos antimilitaristas.

35 Fragmento del prologo de J. Prat a JACQUINET, C. (1907), Ibsen y su obra, Valencia, p. V. 


\section{ÁLVARO GIRÓN}

el ideal ácrata y unos comportamientos guiados todavía por una sociabilidad tradicional, se trata de racionalizar a través del recurso al atavismo. Prat, por ejemplo, constataba que la «anarquía no ha podido aún triunfar ni en el corazón de los hombres ni transformar sus costumbres porque aún no se adentró lo bastante en el cerebro de la mayor parte de los que se dicen anarquistas para poder ser una guía segura de sus actos...» Sin embargo, la idea se encontraba ante un obstáculo formidable ya que debiera constituirse en una «fuerza moral que se sobreponga y anule atavismos y herencias que acaso no se destierren en una o dos generaciones». Y no todo es cuestión de voluntad revolucionaria. Frente a la amenaza del substrato bestial no se encuentran fácilmente soluciones: «No nos falta a los anarquistas este deseo, pero no sabemos como desprendernos del chimpancé primitivo y hereditario que a todos nos gruñe más o menos en el cerebro.» ${ }^{36}$

Lo que sí es claro es el ideal a alcanzar: un Hombre sacralizado, concebido como pura racionalidad (con capacidad de reflexión total), y por tanto con una absoluta auto-soberanía. Se trata de un sujeto incondicionado y con mayúsculas. Un ser que no debiera ser la víctima de una animalidad, de unos instintos primordiales que se esconden en los pliegues más ocultos de la mente, del inconsciente. El objetivo difícil- es aniquilar ese residuo bestial que se concibe como el polo negativo de la plena humanidad. Algunos, como es el caso de Ricardo Mella en 1912, piensan que la Revolución debiera acelerar decisivamente el proceso:

«...habremos de proseguir, en la medida de nuestras posibilidades, la obra de hacer conciencias (...) exaltar la razón sobre el instinto, aniquilar la animalidad para que el hombre surja soberano de sí mismo. La bestia interior gobierna todavía el mundo. La revolución acabará con ella» ${ }^{37}$.

36 PRAT, J. (1901), «A un amigo», Acción Libertaria, 27, 1; p.1. El artículo de Prat es un alegato contra el fanatismo dentro de las filas libertarias. El desencadenante parece ser la oposición de un sector importante del movimiento libertario a la aparición de una nueva publicación. Obsérvese hasta que punto el lenguaje esta permeado de resonancias darwinistas: «Tu querías un periódico que fuese una fuerza intelectual cooperando con otras fuerzas intelectuales en la formación del progreso social, y la gran masa del partido te responde ¡Vade Retro! (...) ¿Qué es esto amigo mío? ¿Struggle for life o kropotkiniana asociación para la vida? PRAT (1911), p. 1. Muy probablemente, Prat se este refiriendo a la fuerte polémica que mantendrá durante estos años Tierra y Libertad y Acción Libertaria. Vid. al respecto: BARRIO Alonso, A. (1988), Anarquismo y anarcosindicalismo en Asturias (1890-1936), Madrid, pp. 100 a 102.

37 Mella, R. (1912), «Las revoluciones», El Libertario, 20, 1; p.1. Urales, bastantes años después, en 1934, retomará la idea de que nos dirigimos a un Hombre con mayúsculas definido por una conciencia de sí absoluta, y por tanto, con una absoluta soberanía de sí mismo: «...el hombre viene del animal todo instinto; en que, el pensamiento, en el instinto se forma; en que el instinto va perdiendo valor así que la conciencia lo gana, y en que el razonamiento es ya la causa de la mayor parte de los actos humanos. Pues bien, este camino que no ha de interrumpirse porque es ley biológica, porque es ley universal, porque está en la especie, está en la tierra y en el sol, conduce a la razón pura, a la responsabilidad completa y, como consecuencia a la completa libertad (...) ¿Para qué esta lucha y esta fase evolutiva si el fin de ella no 
Existe aquí un foco de tensiones, cuando no de contradicciones, que no se salva. A partir de los años 1890, y mucho más claramente, en los primeros años del siglo, la influencia de Kropotkin, y otros autores, lleva a una parcial reivindicación de los primitivos y las sociedades animales ${ }^{38}$. De hecho, se llega a decir que los elementos constitutivos de la vida social, - la solidaridad, el altruismo - son herencia de nuestro pasado evolutivo. El propio Prat en 1903, afirmaba que el «hombre no ha hecho más que agrandar, perfeccionándolo, este espíritu de solidaridad que se halla ya en los demás animales inferiores, antepasados suyos, de los cuales ha surgido, y de los cuales lo heredó» ${ }^{39}$ Entran aquí en colisión la imagen de la historia humana como la ascensión constante desde unos orígenes miserables (representados por la animalidad), y la idea de que la sociedad es una realidad prehumana, natural, anterior en todos los sentidos al Estado. Por otra parte, cuando se trató de atacar la tesis lombrosiana de la criminalidad nativa como pervivencia atávica, se puso en cuestión ocasionalmente el cliché de la ferocidad primitiva. Es el caso del citado Mella en 1913, quien en su artículo, «Salvajismo y ferocidad», critica que se afirme «sin pruebas, la maldad, la bestialidad y la ferocidad del hombre primitivo, reservando para el hombre civilizado una bondad y un humanismo, que si corona triunfalmente la teoría, no por ello está de acuerdo con la realidad». Es más, en una observación bastante perspicaz, cuestiona el uso de la teoría de la recapitulación como supuesto soporte científico de la idea de que la criminalidad no es sino la expresión del animal interior que pervive en los pliegues más ocultos de la mente humana:

\footnotetext{
«Por otra parte, animalidad no quiere decir fatalmente ferocidad. Hay animales fieras; hay animales dulcemente pacíficos. No está demostrado que el hombre sea una fiera en evolución o en domesticación humanizadora, aun 'cuando la biología pruebe que somos el resumen biopsicológico por que ha pasado la especie hasta la aparición del individuo'. Todo lo que se quiera, respecto a las fases por las que pasa el embrión del hombre, siempre quedará en pie la dificultad insuperable de unificar todas las especies en una común característica, sea de fiereza, sea de bondad» 40 .
}

Hay que decir que, a pesar de ello, la visión peyorativa de la animalidad es dominante $^{41}$. Tampoco las amenazas acaban ahí. Aniquilar el animal interior que se constituye en el símbolo vivo de las bases sobre las que está construida la sociedad presente no es suficiente. La herencia de los caracteres adquiridos no sólo hace posible

hubiese de ser la formación del hombre dueño de si mismo, del hombre propiamente llamado tal? URALES, F. (1968), La evolución de la filosofía en España, Barcelona, pp. 225-226.

38 Al respecto vid. GIRON, A. (1996), Evolucionismo y anarquismo en España, Madrid, pp. 94-118.

39 PRAT, J. (1920), Necesidad de la Asociación, Barcelona, p. 5. Este folleto es la transcripción de la conferencia leída en el Centro de la Federación Metalúrgica de Barcelona el 31 de Octubre de 1903.

40 Mella, R. (1926), Ideario, p. 142

41 Vid. GIRÓN, A. (1996), pp. 84. 
que en nosotros perviva el pasado prehumano del género, sino también las ideas, costumbres y prejuicios de nuestros antepasados plenamente humanos. En cierto sentido la historia se hace naturaleza, se incorpora de manera literal. Ya no bastaba, como se decía en La Federación en 1871, que «las generaciones infestadas del horrible virus religioso, y que ya tienen un pie en el sepulcro, desciendan a él cuanto antes $»^{42}$. El virus religioso, de hecho, se transmitía de generación en generación. Hacer tabla rasa de la historia se convertía en una tarea ímproba: El pasado no sólo se objetivaba en instituciones obsoletas como el Estado, la Iglesia o la Propiedad, sino que siglos de educación religiosa, de sumisión y servilismo se introducían en los cuerpos y las mentes de todos con la insidiosa y frecuente complicidad del inconsciente. La Historia, nefasta, vive dos veces.

Ya en 1889, en el Segundo Certamen Socialista, Ricardo Mella, haciéndose eco con toda probabilidad de planteamientos esgrimidos anteriormente por Herbert Spencer, trataba de explicar el origen histórico de la tendencia a la obediencia a la autoridad política. Según el planteamiento del anarquista gallego, es en el tránsito desde la libertad nómada a la cooperación societaria, en el que se produce un extenso periodo de estado de guerra donde en virtud del uso-herencia, «arraigan poco a poco en los hombres las ideas de sumisión y obediencia tanto por adaptación necesaria al medio social como por herencia fisiológica.» ${ }^{43}$ Evidentemente, la internalización de este tipo de disposiciones se convertía en una seria amenaza para una ideología que rechazaba la política como elemento de mediación en las relaciones humanas. Pero el anarquismo era también un proyecto encaminado a crear un hombre nuevo desde base enteramente racionales. Desde este punto de vista, la persistencia de conductas irracionales o de pasiones humanas como los celos solían ser explicadas como el resultado del proceso de inculcación formal o informal que se produce en una sociedad donde la religión, la superstición o el respeto a la propiedad privada ocupan un lugar eminente. El problema se hace más grave cuando la herencia de los caracteres adquiridos permite que la acción nefasta del medio social se perpetúe en las generaciones sucesivas. Anselmo Lorenzo, por ejemplo, afirmaba que las «pasiones arraigadas en el tiempo, transmitidas por la costumbre y aún aumentadas por la selección [nota del autor: Lorenzo confunde herencia de los caracteres adquiridos y selección

42 Redacción (1871), «Sección varia», La Federación, 74, 3-4; p. 4.

43 Mella, R. (1890), «La anarquía», en Segundo Certamen Socialista, Barcelona, 54-71; p. 59.El recurso a la influencia hereditaria para explicar la tendencia a la aceptación de la autoridad política y la sumisión al sistema legal no es exclusivo del anarquismo español. El ruso Pedro Kropotkin, uno de los dirigentes anarquistas internacionales más influyentes afirmaba que la «idea que el ser humano tiene de su incapacidad le hace concebir la conveniencia de la ley y ésta (...), influye en los actos del hombre de tal modo, que alcanza fuerza hereditaria». De ahí concluía que «el hábito y la herencia nos obligan a tener que elegir director». KROPOTKIN, P. (1901), «Autoritarismos», La Protesta, 98, 1, p. 1. 
natural] y consagradas por las leyes forman una masa enorme de funestas influencias y de grandes obstáculos (...) que a todos obligan, coartan y determinan.... ${ }^{44}$

Pero no se trata sólo de los individuos. Algunos anarquistas, como Ricardo Mella, postulaban un modelo alternativo de sociedad nueva en el que el sistema legal y la coerción del Estado serían sustituidos por la acción de la censura del grupo social inmediato. Sin embargo, es el propio espíritu colectivo el que está corrompido por las falsas preocupaciones y las costumbres ridículas. No poco de esto procede de «la herencia». La emancipación de estos «errores tradicionales» no es tarea fácil ya que es el propio Estado y sus leyes, los que «por medio de organismos de desmoralización y de espionaje, mantienen y fomentan los efectos de la transmisión hereditaria» ${ }^{45}$.

Como se puede deducir de lo dicho hasta ahora, el planteamiento que hacen los anarquistas españoles sobre la cuestión parte, en apariencia, de un ambientalismo extremo. Los seres humanos son, en gran medida, el resultado combinado de la acción de los medios sociales del presente y del pasado: no hay una bondad o maldad nativas desde un punto de vista estricto. En cierto sentido se puede decir que la naturaleza humana se socializa enteramente. Sin embargo, la imagen esencialista y racionalista del hombre, especialmente arraigada en la ideología política del anarquismo español, supone un freno poderoso a esta tendencia aparente. Existe un núcleo duro de la naturaleza humana — caracterizado, entre otras cosas, por su bondad- no moldeable por los ambientes presentes y pasados. La razón no es una razón situada social e históricamente, sino una esencia trans-histórica. De hecho, la contradicción entre ese empirismo nominal extremo y la visión esencialista de las cosas (donde la Razón, el Hombre y la Naturaleza actúan como entes sacralizados), no se salva ${ }^{46}$.

Por otra parte, la Historia, es decir, todo el devenir del homo sapiens desde la formación de las primeras agrupaciones sociales hasta la sociedad presente, se solía ver como una sucesión de estadios en que el progreso industrial y científico son evidentes. Pero mucho más evidente parece que ese devenir arrastra un defecto de naci-

44 LoRenzo, A. (1890)b. «Previsión de un juicio futuro», en Segundo Certamen Socialista, Barcelona, 255-262; p. 260.

45 Mella, R. (1901), pp. 28-29. Mella manifiesta aquí algunas dudas sobra las leyes de la herencia fisiológica: «Aún cuando la herencia fisiológica sea una ley todavía discutida, y la transmisión (...) de aptitudes y tendencias no constituya un principio bien comprobado, nosotros empleamos la palabra herencia en el sentido de que ciertas ideas y sentimientos, ciertas inclinaciones y disposiciones permanecen invariables en desenvolvimiento de los pueblos, porque de todos modos los hechos persisten a pesar de que la teoría que los explica no se halle sólidamente establecida.» MELLA (1901), p. 28. Sin embargo, años después, hablando del «verbalismo atávico» tiene menos dudas, afirmando que la «herencia es más poderosa que nuestra razón y nuestra voluntad», encontrándose en «el determinismo físico y social» la «explicación para el fenómeno.» MELlA, R. (s.f.), Cuestiones de Enseñanza. Estudios pedagógicos, Barcelona, p. 25.

46 Sobre dicha contradicción: AlvareZ JunCO, J. (1991), La ideología política del anarquismo español, Madrid, p. 52. 
miento: las sociedades presentes y pasadas perpetúan la división entre amos y esclavos, aristócratas y siervos, burgueses y proletarios, dominadores y dominados ${ }^{47}$. La incorporación del pasado mediante la herencia de los caracteres adquiridos no hace, en este sentido, sino reforzar esta tendencia a la perpetuación del mal moral y social. Y más que de incorporación cabe hablar de infección o de lesión ${ }^{48}$, ya que no se trata tanto de moldear la materia indefinidamente proteica del individuo, sino de la inserción de unas disposiciones negativas que se superponen patológicamente sobre el sustrato esencialmente bueno del ser humano.

Puede que todo esto sea criticable desde el punto de vista lógico, pero representa claros beneficios ideológicos. El mal no viene de una Naturaleza sacralizada, sino de una organización social viciosa. Joan Montseny, por ejemplo, llegaba a afirmar que «la naturaleza en sí, sin participación extraña, no produce enfermos.» No existe tampoco criminalidad «natural» como querían hacer ver Lombroso y sus discípulos, porque, en definitiva, las «enfermedades hereditarias, estas enfermedades que nos presentan como defectos naturales, y por consiguiente como obstáculos naturales también, para la reforma social que los anarquistas propagamos, son producidas por la sociedad y por ellas fomentadas» ${ }^{49}$. Y no sólo la enfermedad mental y la criminalidad no son naturales, tampoco lo son las bases sobre las que se constituye la familia burguesa. Según afirmaba en 1903 Andrés Cruz, uno de los traductores de La moral anarquista de Pedro Kropotkin, «la actual constitución de la familia» obedece, «como en los primeros tiempos de las organizaciones políticas, a un plan social puramente autoritario, y su mayor fuerza estriba en la propiedad individual y en las costumbres atávicas, pero a ningún sentimiento natural y espontáneo». En una significativa contradicción señalaba, además, que los «gritos de la sangre son los de la regresiva herencia, que da carácter de sentimientos innatos y naturales a los que no son sino hijos del hábito» ${ }^{50}$.

47 Subyace a esto una imagen eminentemente bifásica del proceso histórico, en «el cual la frontera entre la era del conflicto y la de la realización plena del hombre viene trazada por un acto puntual, la insurrección urbana, de barricada, al que seguiría en el planteamiento republicano, el sufragio universal y la integración económica del proletariado en la sociedad burguesa, y en la anarquista "la liquidación social", la disolución de la vieja sociedad y la abolición del Estado». ELORZA, A. (1990), «La cultura de la revuelta en el siglo XIX», en Maurice, J., Magnien, B. y Genevois, D.B. (dirs.), Pueblo, movimiento obrero y cultura en la España contemporánea, París, 127-139; pp.138-139.

48 A veces en un sentido casi literal. Es el caso de Joan Montseny (en este caso utiliza el seudónimo de Federico Urales), quien pensaba que el hábito inculcado por la religión católica de despreciar la carne, la materia, había tenido como resultado una generación que era incapaz de sentir placer: «La existencia de hoy no es placer, por el atavismo que han dejado en nuestro cerebro y organismo generaciones, que considerando el sufrir como un gran bien para el alma, maltrataron la materia y la dejaron incapaz para sentir y para desear placeres». URALES, F (1899), «Socialismo y cristianismo», La Revista Blanca, 14, 387-390; p. 388.

49 MONTSEnY, J. (1896), pp. 81 y 88.

50 CRUZ, A. (1903), «La evolución social», El Productor, 28, 1-2; p.2. 
Por tanto, la herencia se sitúa en el lado de las fuerzas que se oponen al cambio social: las costumbres, los hábitos colectivos, lo no reflexionado o inconsciente como lastre del progreso humano. Frente a este magma indiferenciado se alzan como motores privilegiados del progreso humano la razón individual y, como no podía ser de otra manera, la Ciencia ${ }^{51}$. Algunos no anarquistas, como Nordau en una serie de artículos aparecidos en Acracia en 1887, eran pesimistas a este respecto. Nordau pensaba que «en la esfera de lo inconsciente, la superstición primitiva continúa obrando, gracias a la ley de herencia», que ello explicaba cómo «la superstición (...) se manifiesta en personas de ilustración excepcional» y concluía que «se necesitarán miles de siglos para que el hombre venga inclinado por su nacimiento a considerar los fenómenos del mundo y de la vida de una manera científica y racional, cien generaciones le habrán precedido en esta vía» ${ }^{52}$. Un anarquista como Anselmo Lorenzo no estaba dispuesto a esperar tanto. En nota al calce al texto de Nordau aceptaba «el valor científico de las afirmaciones del autor sobre la herencia» pero rechazaba «el pesimismo que sustenta». El anarquista toledano pensaba que «la duda, el escepticismo y las convicciones científicas individuales (...) constituyen atenuantes importantísimos a la transmisión hereditaria de la superstición, y acerca el periodo del dominio absoluto de la ciencia» ${ }^{53}$.

Y si frente a la superstición está la ciencia, frente a la irracionalidad del pasado (las pasiones) sólo pueden estar, una vez más, la razón, el pensamiento. Pero, ¿qué tipo de pensamiento? Lorenzo en el Segundo Certamen Socialista (1889) manifiesta

51 El anarquista francés Charles Malato lo dice aún con más propiedad: «"El movimiento es universal, pero puede ejercerse en direcciones diferentes; ser progreso y regresión". Dos fuerzas rivales se disputan al hombre: una el atavismo, le inclina al pasado, transmitiendo en la sangre las costumbres y las maneras de ser de sus ascendientes; otra, la fuerza evolutiva, que Bakunin glorificaba bajo el nombre de espíritu de rebeldía, impulsa al individuo hacia modos nuevos y le obliga no sólo a adaptarse a los cambios del medio ambiente, sino hasta rebelarse contra él cuando no se transforme con la rapidez necesaria". Toda la vida humana es un duelo incesante entre esas dos fuerzas, entre las costumbres y la razón, aquellas torpes y retrasadas siempre respecto de ésta”.» Fragmento citado en TÁRRIDA, F. (1899), «Carlos Malato», La Revista Blanca, 19, 583-541; p. 540.

52 NordaU, M. (1887a), pp. 317-318. Es interesante destacar un hecho al hilo de lo señalado por Nordau: los anarquistas también creían que los elementos más instruidos del movimiento libertario podrían no estar al abrigo de las influencias atávicas. La preocupación por una súbita conversión atávica de los elementos conscientemente libertarios o simplemente materialistas es visible en la novela de Joan Montseny Sembrando Flores, que fue encargada por Francisco Ferrer como libro de lectura de la Escuela Moderna. El protagonista, Floreal Ramos, preocupado por el hecho de que en su vejez o en la hora de su muerte pudiera renegar de su ideal materialista, lo resume en unas cuartillas. Y declara que si dijese o hiciese algo en contra de lo que dicen las cuartillas, «entiéndase que se me habrá arrancado en horas de debilidad y con malas artes o que habrá sido pensado en momentos en que se descomponía mi pensamiento, o lo habré sentido al soplo de esta autoritaria y servil herencia que nos han dejado generaciones pasadas con sus siglos de servidumbre y de ignorancia mental y material». URALES, F. (1935), Sembrando Flores, Barcelona, p. 186.

53 Incluido en NORDAU, M. (1887a), p. 318. 
su preferencia por la utopía. El espíritu de rebeldía, la «investigación científica», ofrecen nuevos argumentos para la crítica de la sociedad presente, y, sobre todo, «abren horizontes a la imaginación» ${ }^{54}$. Ahora bien, aquí Lorenzo quiere dar una solidez a la fuerza de la imaginación utópica. La herencia conservadora, ahora preserva ese carácter adquirido, es decir, nuevo que constituye toda exploración sobre lo posible en el terreno sociopolítico. Y así, la herencia, mantenedora casi siempre de la «rutina», se «convierte en sostenedora de las ideas que germinan y fructifican, hasta declarar caducos los antiguos moldes humanos y dar vigor y pujanza a las corrientes de nueva vida para que, a semejanza de las revoluciones geológicas, dejen reducidas a la categoría de estratificaciones a las antiguas sociedades.... ${ }^{55}$

Ya no es solo el espíritu de rebeldía, la imaginación utópica. En el proyecto iluminista del anarquismo español de transformación de la sociedad y del individuo sobre bases racionales ocupaba un lugar eminente la educación. Aquí también preocupaban los efectos nefastos de la herencia. Montseny creía que limpiar el residuo hereditario que habitaba en la mente infantil era uno de los objetivos prioritarios de la labor educativa ${ }^{56}$. Más significativo es que en el círculo de Francisco Ferrer Guardia también preocuparan los efectos negativos de la transmisión hereditaria. En el Boletín de la Escuela Moderna, se constata que por «ley de herencia» se acentúan las tendencias pasivas de los jóvenes, que es esta misma ley la causa de que el niño sea «egoísta», y se propone como objetivo fomentar «la evolución progresiva de la infancia evitando atavismos regresivos» ${ }^{57}$. De hecho, para la primera directora de la Escuela Moderna, la francesa Cleménce Jacquinet, «la educación es el antídoto de la herencia». Sin embargo, la perspectiva pedagógica desarrollada por Jacquinet difería de la de Urales. No se trataba de efectuar una acción directa sobre el niño (limpiar su mente), sino de elaborar una estrategia indirecta basada en establecer las condiciones ambientales propicias que atenúen o detengan el desarrollo de las tendencias negati-

54 LoREnZO, A. (1890)b., p. 261. La Ciencia tiene aquí la función de establecer un horizonte positivo - una legitimidad- tanto a la crítica de la sociedad presente («... observación de un hecho que hiere una preocupación...»), como a la exploración de nuevas formas de organización social emprendida por la imaginación utópica (se «abre horizontes a la imaginación»). Sobre la utopía como experimentación sobre lo posible y su emparentamiento con la imaginación: RICOEUR, P. (1989), Ideología y utopía, Barcelona, pp. 325-326 y RICOEUR, P. (1986) Ética y cultura, Buenos Aires, pp. 110-111.

55 LORENZO, A. (1890)b., p. 261. Aquí se puede decir con Radl: «La variación introduce nuevas posibilidades en la vida, representa un elemento progresivo. La herencia fija caracteres y es conservadora. Pero como los que fija son caracteres adquiridos, contribuye al progreso.» RADL (1988), p. 300.

56 «Habrá que borrar con buena esponja y con agua clara (y aquí también somos redichos) lo que la ignorancia y la historia escribieron en la mente de los niños muy antes de nacer. Los padres habrán de ser educados para tan delicada labor. De así hacerlo, cuando este niño sea padre tendrá la mente más limpia y clara, mejor dispuesta que sus antepasados para limpiar la de sus hijos y la de sus nietos, que no se borrará por completo en una, en dos, ni en tres generaciones lo que el tiempo escribió en nuestras almas que vuelan» URAles, F. (s.f.), Pedagogía social. Cómo educar a los hombres, Barcelona, p. 20.

57 FERrer, F. (1976), La Escuela Moderna, Madrid, pp. 43, 71 y 135. 
vas latentes. Es decir, que lo que «el educado requiere es un amoroso e inteligente condicionante que de un lado le distraiga de los elementos del medio que le hacen desarrollar las malas disposiciones hereditarias, y del otro lado, que le impulse a absorber substancia del ideal destinado a ser la realidad del mañana» ${ }^{58}$. Pero aquí Jacquinet detecta un grave problema. Admitir que la herencia fija los caracteres adquiridos, ya sea por una influencia ambiental difusa, ya sea por la mera inculcación puede llevar a consecuencias turbadoras. La responsabilidad del pedagogo y el educador se amplía espectacularmente. El influjo de la acción educativa se puede extender a generaciones sucesivas. Desde este punto de vista, tiene gran importancia una pregunta de difícil respuesta que se hace Jacquinet: «¿Qué caracteres (...) conviene hacer adquirir y fijar en nuestros hijos? ${ }^{59}$

Concluyendo, diremos que los anarquistas españoles, aunque nunca desarrollaron una reflexión coherente sobre el debate existente sobre los mecanismos responsables de la herencia fisiológica, aceptan implícitamente la lamarckiana herencia de los caracteres adquiridos. La conexión establecida hasta la saciedad entre herencia y memoria entre los años 1870-1930 en el discurso científico y literario, se articula de manera muy particular en el anarquismo español y no se reduce desde luego a la difusión piramidal de una serie de conocimientos difundidos por las elites culturales. La analogía herencia/memoria permite dar un apoyo científico, una explicación más o menos convincente a la persistencia de aquellas disposiciones individuales y colectivas que obstaculizan la emergencia del hombre nuevo antes y después de la Revolución. Lo hereditario, que se identifica fácilmente con lo inconsciente, el animal interior o simplemente con prejuicios o costumbres tradicionales, se convierte en un obstáculo formidable a la hora de hacer tabla rasa de la Historia. Visto así, el recurso a la herencia se subordina a un esquema narrativo mayor que le precede y que tiene su sustrato último en las raíces ilustradas de la ideología del anarquismo español: la regresiva herencia es un elemento más de las metáforas que aluden a la lucha entre

\footnotetext{
58 JACQUINET, C. (1902), pp. 42-43..

59 Fragmento de «Factores de educación social», incluido en JACQUINET (1907), p. 196. Aunque Jacquinet fue la primera directora de la Escuela Moderna, ya en el tercer año deja de formar parte de la gestión pedagógica de la escuela, y abandona su colaboración con el Boletín de la Escuela Moderna. En opinón de Pere Solà, la sustitución de Jacquinet, quien dio el tono pedagógico-ideológico de los primeros años de la Escuela, marca un camino (encabezado por el propio Ferrer y Anselmo Lorenzo), que abandona lo que se consideraba excesivo neutralismo ideológico de la francesa. Se acentúa así la ideologización crítico social del alumnado (SOLÀ I GUSSINYER, P. (1980), Educació i movement llibertari a Catalunya (1901-1939), Barcelona,pp. 86, 112 y 139). Sin embargo, esta nueva orientación no dejo de ser criticado por algunos anarquistas, como Ricardo Mella, quienes criticarán el doctrinarismo de las escuelas racionalistas (Alvarez JunCO (1991), pp. 537-538). Ahora bien, este género de críticas, en opinión de Pere Solà no hacen sino seguir una línea muy parecida a la indicada por Jacquinet anteriormente. Vid. SoLÀ I GUSSINYER, P. (1977), «Escuela y educación para una sociedad autogestionada: la aportación de la pedagogía racionalista de F. Ferrer», en MONÉS, J., SOLÀ, P y LÁZARO, L.M. (1977), Ferrer Guardia y la pedagogía libertaria, Barcelona, 59-113; p. 81.
} 
pasado y futuro, irracionalidad y Razón, superstición y Ciencia. Sin embargo, no todo es idealismo en el movimiento libertario. La extensión de las convicciones científicas o la difusión de una educación basada en la Razón, no asegura la transformación del ser humano. Existe un factor limitativo externo mucho más poderoso: la forma en que está organizada la sociedad presente basada en la desigualdad. No hay revolución cultural-personal sin revolución social-material. Ricardo Mella, en su folleto de 1900 Del amor: modo de acción y finalidad social, lo hace ver claramente. No basta con eliminar la basura hereditaria para que se generalicen relaciones armónicas y fraternales entre los hombres:

«A ser posible extinguiríamos en todos los hombres hasta el último residuo de esa herencia bestial, de esa herencia de crímenes interminables (...) emancipáos cuanto podáis de la herencia maldita (...) Limpiad la basura hereditaria; despojáos, por las más puras prácticas de la afectividad y más altas de la inteligencia de los últimos residuos de la animalidad primitiva; pero cuando queráis amar (...) se levantará ante vosotros una valla insuperable: la valla de la desigualdad que os hace esclavos» ${ }^{60}$.

60 Citado en Cano, B.N. (ed), El pensamiento de Ricardo Mella, México, pp. 143-144. Este folleto aparece publicado por primera vez en la Biblioteca Geopolita de Buenos Aires en 1900. 